
\title{
BReserch S Suare \\ Prediction of Unconfined Compressive Strength of Microfine Cement Injected Sands Using Fuzzy Logic Method
}

\section{Eray Yildirim}

Bursa Technical University: Bursa Teknik Universitesi

Eyubhan Avci ( $\nabla$ crowner06@mynet.com)

Bursa Teknik Universitesi

Nurten Akgün Tanbay

Bursa Technical University: Bursa Teknik Universitesi

\section{Research Article}

Keywords: Fuzzy logic, Mamdani, Sugeno, Regression, Unconfined compressive strength

Posted Date: November 1st, 2021

DOI: https://doi.org/10.21203/rs.3.rs-232296/v1

License: (c) This work is licensed under a Creative Commons Attribution 4.0 International License.

Read Full License 


\title{
Prediction of Unconfined Compressive Strength of Microfine Cement Injected Sands Using Fuzzy Logic Method
}

\author{
Eray Yildirim ${ }^{1}$, Eyubhan Avci ${ }^{2 *}$, and Nurten Akgün Tanbay ${ }^{3}$
}

\author{
${ }^{1}$ Assistant Professor, Dept. of Civil Engineering, Bursa Technical University, Bursa 166330, Turkey, \\ eray.yildirim@btu.edu.tr \\ ${ }^{2}$ Associate Professor, Dept. of Civil Engineering, Bursa Technical University, Bursa 166330, Turkey, \\ eyubhan.avci@btu.edu.tr (Corresponding Author) \\ ${ }^{3}$ Assistant Professor, Dept. of Civil Engineering, Bursa Technical University, Bursa 166330, Turkey, \\ nurten.akgun@btu.edu.tr
}

\section{Abstract}

In this study, unconfined compressive strength values of sand soil injected with microfine cement were predicted using fuzzy logic method. Mamdani and Sugeno methods were applied in the fuzzy logic models. In addition, a regression analysis was carried out in order to compare these two methods. In the models, water/cement ratio and injection pressure were the input variables, and unconfined compressive strength was the output variable. The dataset includes 427 samples, which were experimentally injected with microfine cement. Predictions for unconfined compressive strength were obtained by creating membership functions and rule base for each input (predictive) parameter in fuzzy logic models. The coefficient of determination $\left(\mathrm{R}^{2}\right)$ and Mean Square Error (MSE) were used as criteria for evaluating the performance of the developed models. The results suggested that the three applied models (i.e. Mamdani, Sugeno and regression) provided statistically significant results, and these methods could be used in the future prediction-based studies. The results showed that Sugeno model provided the best performance for predicting unconfined compressive strength. It was followed by Mamdani and Regression models, respectively. This study has suggested that the fuzzy logic 
method can be an alternative to the regression method which traditionally has been used in prediction process.

Keywords: Fuzzy logic; Mamdani; Sugeno; Regression; Unconfined compressive strength

\section{Introduction}

Many techniques are used in geotechnical engineering to improve the geotechnical properties of soils. In the commonly used injection technique, a suspension or solution type material is injected into the voids of soil and/or rock under pressure (Karol, 2003). Permeation injection is the most widely used technique and it is the process of injecting material into voids in the soil under low pressures without causing any displacement and/or hydraulic fracture. Following injection, some engineering properties of the soil, such as strength and permeability, improve.

Portland cement is widely used in permeation injection applications. Due to the large particle size of Portland cement $\left(\mathrm{D}_{100}=100 \mu \mathrm{m}\right)$, its injectability is limited to coarse sands. Chemical injection materials emerged with the motivation to find materials that could be penetrated into small particle size soils. The application areas of chemical injection materials are limited due to their high cost, low strength, and toxic effect. The search for injection materials with smaller particle sizes, which can be an alternative to chemical injection materials, and the reduction of the particle size of Portland cement led to the emergence of microfine cements. Cements with a particle size less than $15 \mu \mathrm{m}$ are defined as microfine cements by American Concrete Institute (Perret et al., 2000). Several types of microfine cements are produced in different names. The most widely known of these cements are Allofix MS, MC-100, Microdur RX, Micromix, Finosol X, Microcem B, Superfine L, Ultrafine 12 and Spinor A12. Regarding the experiments carried out by Tekin (2011), 
microfine cement suspension provided very good rheological properties. Zebovitz et al. (1989), Karol (2003) and Warner (2003) stated that grouting could be performed easily for materials ranging from microfine cements to fine sands. Christodoulou et al. (2009), Markou and Droudakis (2013), Hashimoto et al. (2016) observed that the strength of the sands increased after microfine cement was injected. Schwarz and Krizek (1994) and Avci (2019) suggested that the permeability coefficients of sands decreased after injecting microfine cement.

Fuzzy logic is a technique in artificial intelligence, and it is widely applied to various areas of science and engineering. This technique is also used for the solution of various problems of geotechnical engineering. Chuang (1995) used fuzzy logic method to evaluate the shear strength of soils. The study aimed to obtain more consistent results between shear strength parameters measured in field and laboratory environments. In this context, fuzzy sets were formed by expressing the anisotropy of the soils, the effect of loading rate and sampling. The shear strength of soils was predicted by using the input parameters. Huang and Siller (1997) developed a fuzzy logic model for geotechnical field characterization using samples collected from drilling studies. In their study, fuzzy sets were created by using the plasticity characteristics for field characterization. Thus, soil profiles could be defined with the developed fuzzy system. Saboya et al. (2006) conducted a study on slope stability using fuzzy logic method. Failure potential index was calculated using the data which included slope angle, height, and permeability. Failure index definitions were defined with linguistic terms as very low, low, medium, high and very high in the fuzzy logic method. Reddy et al. (2009) carried out a study, which utilised the Mamdani method, on the identification of swellable soils and determination of the swelling potential using the fuzzy logic approach. Liquid limit, swelling index, shrinkage limit, and plasticity index parameters were defined as input parameters while swelling potential was the output parameter. Zorluer et al. (2010) used fuzzy 
logic approach to determine clay dispersibility. The dispersibility of 29 samples were examined using the fuzzy logic technique, and it was found that reliable results were obtained. Yurtçu and Özocak (2016) studied on predicting the compression index values of fine grained soils using artificial neural networks and fuzzy logic methods. Çavuş et al. (2019) developed a method for determining the liquefaction potential of soils using the fuzzy logic method. The developed fuzzy logic based method was compared with field observations and semiempirical methods. It was found that the fuzzy logic method has a significant potential for geotechnical engineering problems.

The study in this paper aimed to predict the unconfined compressive strength values of sand soil grouted with microfine cement by using the fuzzy logic methods. Mamdani and Sugeno methods were used in fuzzy models. In addition, regression analysis was conducted in order to make a comparison with the applied fuzzy logic methods. In all three models, the same inputs and output values were used to make a comparison. Water/cement ratio and injection pressure were predictors and unconfined compressive strength values were the outcome variable.

\section{Experimental Study}

\subsection{Materials Used in Experiments}

In the injection experiments, river sand (quartz sand) sample taken from Kiz1lirmak river was used. The sand sample was divided into two groups by using sieves. The soils between No 10 and No 40 sieves were grouped as medium sand, and the soils between No 40 and No 200 sieve were grouped as fine sand. Then, the grouped samples were mixed in different proportions to obtain 11 different gradations, and injection experiments were performed with these gradations (See Fig. 1). Two microfine cements with maximum particle sizes of $6 \mu \mathrm{m}$ and $12 \mu \mathrm{m}$ were used in the injection experiments. 


\subsection{Injection and Unconfined Compressive Strength Tests}

The experimental setup consists of 40 injection molds, a compressor, an injection tank, a manometer and fittings. The injection mold was made of polypropylene random copolymer material with a diameter of $52 \mathrm{~mm}$ and a height of $120 \mathrm{~mm}$, and the upper and lower heads were made of caestamide material. The vibratory hammer was used to adjust the desired relative density for placing the soil into the molds. The injection system included a gearmotor rotating at $100 \mathrm{rpm}$ and pedals connected to the motor. Detachable (pneumatic) pipes were used as fasteners in the injection system. Samples were placed in the mold in three layers with five different relative densities of $30 \%, 40 \%, 50 \%, 60 \%$ and $70 \%$. In order to facilitate the removal of the injected sands from the molds, the inner surface of the mold and the heads were lubricated. Sands were placed in the mold, and a filter material made of coarse sand with a thickness of $0.8 \mathrm{~cm}$ was placed on the lower and upper head of the mold. Then, the molds were placed in the injection system and injection tests were carried out.

The samples that were successful in the injection tests were removed from the molds and placed in the curing tank. In the end of the 150th day, the samples, which were kept in curing tank, were tested for determining unconfined compressive strength according to the ASTM D4219-02 (2002) standard. Prior to the unconfined pressure tests, a cap made of plaster was constructed for the top and bottom sections of the samples.

\section{Fuzzy Logic}

Artificial intelligence is defined as a system that exhibit behaviours specific to human intelligence. With artificial intelligence, systems perceive problems and also exhibit behaviours such as learning, thinking, making decisions and making predictions. Main methods of artificial intelligence are fuzzy logic, artificial neural networks, adaptive neurofuzzy inference systems, genetic algorithms, expert systems and data mining. These methods 
have several application areas such as in health, image processing, prediction, planning, and optimization. Regarding the state of the art review, fuzzy logic method was used in this study. The concept and the theory of fuzzy logic were developed in 1965 by Zadeh. Classical logic uses binary values (0-1); while, in fuzzy logic, it is assumed that the variables can have intermediate values (as the glass is half full, the color may be gray). Therefore, the fuzzy logic can provide more flexible predictions. In fuzzy logic, values (information or data) are specified in linguistic terms such as little, big, much, less. The data can take a value between between 0 and 1 (Zadeh, 1965). In fuzzy logic, calculations are made with rules based on the relationships between linguistic expressions. The mathematical model of fuzzy logic is very suitable for application in systems that are very difficult to construct (Elmas, 2003). Fig. 2 shows the processing scheme of the fuzzy inference system.

The first step in the fuzzy inference system is fuzzification of the input variables. This is followed by generating the fuzzy rule base. The third stage is to obtain the results of fuzzy input values with the help of the rules. The last step is defuzzification of the results. For a classical A set, if the element $\mathrm{x}$ is a member of the set, it takes the value 1 ; if it is not, it takes the value 0 (Eq. (1)).

$\mu_{A}(x)= \begin{cases}1, & x \in A \\ 0, & x \notin A\end{cases}$

Contrary to the classical set, a fuzzy set is defined by the membership function $\mu_{A}(x)$, which can take values between 0 and 1 in space U (Eqs. (2) and (3)) (Monjezi et.al., 2009). Elements in the fuzzy set are expressed linguistically.

$A=\left\{x, \mu_{A}(x) \mid x \in U\right\}$

$\mu_{A}(x)=\left\{\begin{array}{c}1, \text { if fully included in the fuzzy set } \\ {[0,1], \text { if partially included in fuzzy set }} \\ 0, \text { if not included in the fuzzy set }\end{array}\right.$ 
here, $\mu_{A}(x)$ is the membership function. $\mathrm{X}$ values correspond to the membership value in the 0-1 range. Triangle, Gaussian and trapezoidal are the most widely used membership functions in the fuzzy logic. Relationships between fuzzy sets are defined on rule basis. Rules are defined with conditionals. Following the formation of the fuzzy rule base the inference process is started. The most commonly used inference methods in fuzzy logic are Mamdani and Sugeno inference systems. In this study, both inference systems were used. The Mamdani inference system is close to human perception. This system can be created very easily, and its interpretability is easier than the Sugeno approach. Since the result has a precise value in Sugeno inference system, it is generally preferred in control related problems. The main difference of this method from the Mamdani inference method is that the output values are defined as functions. In Sugeno method, inputs are defined with fuzzy sets, while output calculations are performed in a functional manner.

Defuzzification is the process of converting the results (fuzzy outputs) obtained from fuzzy calculations into numerical values. There are several defuzzification methods available, and in this study, the center of gravity method, which is the most commonly used defuzzification method, is chosen. In this method, the center of gravity of the aggregated fuzzy results of output membership functions is calculated to convert the outputs into numerical values (Eq. (4)) (Nurcayho, 2003).

$x_{C O A}^{*}=\int \frac{\mu_{A}(x) \cdot x d x}{\mu_{A}(x) d x}$

where, $\mu_{A}(x)$ is the membership function.

\section{Implementation of Models For Prediction of Unconfined Compressive Strength}

Fuzzy logic (Mamdani and Sugeno) and regression analysis were carried out using the obtained 427 data. MATLAB was used in the creation of models, operations and analysis. The unconfined compressive strength values of the injected samples were predicted by using 
created models. In both fuzzy logic and regression analysis, unconfined compressive strength values were used as outcome variables, and water / cement ratio and injection pressure values were used as predictors (See Fig. 3).

Membership functions of inputs (water / cement and injection pressure) and outputs (unconfined compressive strength) are shown in Fig. 4. Triangular and trapezoidal membership functions were used in creating models, and the degree of membership was normalized between 0-1. Membership functions were defined by using linguistic terms and fuzzy sets were defined by these expressions (VL: Very Low, L: Low, ML: Medium Low, M: Medium, MH: Medium High, H: High, VH: Very High). After creating membership functions and linguistic terms for inputs and outputs, the rules were formed. The number of rules and rule base were determined by expert opinion. Ten rules were formed for the Mamdani method. These rules are presented in Table 1.

For the Sugeno method, the rules were formed by using the linear relationship between input and output variables. Similar to the Mamdani method, ten rules were defined for the Sugeno method. These rules are given in Table 2. The linear relationships shown in Table 2 were obtained from the available data.

In this study, in addition to fuzzy logic, regression analysis, which is the most traditionally used approach in prediction problems, was also performed. In regression analysis, relation between output and input variables is expressed by a functional relationship. Multiple linear regression was utilized. The relationship used for multiple linear regression analysis is;

$Y=B_{0}+B_{1} X_{1}+B_{2} X_{2+} B_{3} X_{3}+\cdots B_{k} X_{k}$

where $Y$ is the output variable, and $X_{i}, i=1, \ldots, k$ indicate the input predictors, and $B_{i}, i=$ $1, \ldots, k$ are the prediction coefficients. The unconfined compressive strength was taken as the 
output variable (i.e. predicted variable), while the water / cement ratio and injection pressure were the input predictors in the regression model.

\section{Results and Discussion}

Results for predicting the unconfined compressive strength values were obtained with the Mamdani and Sugeno fuzzy logic methods, and the regression analysis. The results were obtained with rules and the defuzzification processes of Mamdani and Sugeno methods. In Fig. 5, a graphical illustration for the calculation of numerical values based on the fuzzy logic models is given where the water / cement ratio as 2.3 and the injection pressure is $145 \mathrm{kPa}$. According to these input values, the unconfined compressive strength is found to be $8.55 \mathrm{MPa}$ and 7.91 MPa with the Mamdani and Sugeno methods, respectively.

Fig. 6 shows the 3D surface viewers of the models used in the study. The graphs in Fig. 6 consist of two horizontal $\left(\mathrm{X}_{1} ; \mathrm{X}_{2}\right.$, injection pressure; water/cement ratio) and one vertical components (Y, unconfined compressive strength). Fig. 6(a) shows the graph obtained from the regression analysis, while Figs. 6(b) and 6(c), show the control surfaces of Mamdani and Sugeno methods, respectively. A single output value was calculated for certain input values with the fuzzy logic method, and the control surface was formed to observe the values that the output will have against the inputs in the fuzzy inference system.

As can be seen from Fig. 6, the surfaces obtained in all three models were similar to each other. Surfaces obtained with fuzzy logic were not linear, but rather wavy or non-linear surfaces. While it was possible to define the surface formed in the regression model mathematically, it was not possible to explain the surface created by fuzzy logic in such manner. In fact, this situation is suitable for problems for which a mathematical relation cannot be expressed explicitly between input and output variables although it is known to exist. The effects of input variables on the unconfined compressive strength values can be 
seen in all three graphs. It is possible to predict the unconfined compressive strength from the inputs for all the models by using these plots.

The coefficient of determination and the MSE values were used to measure the performance of the models. First, the predicted unconfined compressive strength values for each input value were calculated. Then, the scatterplot of the measured unconfined compressive strength value was drawn with the predicted unconfined compressive strength as shown in Fig. 7. Linear simple regression analysis was applied to the scatter plots, and the $R^{2}$ was determined. The $R^{2}$ can have values between 0 and 1 . The $R^{2}$ value is a criterion that shows the consistency and performance of the relationship between the predicted and measured values. If $R^{2}$ is close to 1 , there is a strong relationship between input and output variables. On the other hand, a value of $R^{2}$ close to 0 indicates a weak relationship. The $R^{2}$ values of the models are presented in Fig. 7.

The MSE is defined as;

$M S E=\frac{1}{n} \sum_{i=1}^{n}\left(Y_{i}-\hat{Y}_{t}\right)^{2}$

where $Y$ and $\hat{Y}$ are the measured and predicted values, respectively. MSE is one of the most widely used criterion to measure the prediction performance of statistical models. A small MSE value indicates that the predicted values are close to the measured ones. The MSEs of the three models are presented in Table 3.

The $R^{2}$ values of all models were higher than 0.86 , and the MSEs were low (Table 3 ). It was seen that the models were successful in predicting the unconfined compressive strength value of sand soils injected with microfine cement. The results presented in Table 3 indicated that the prediction performances of the three models were close to each other. The $R^{2}$ values of fuzzy logic methods were relatively higher than that of the linear regression, and the MSE of these methods were lower than the regression approach. Hence, it could be stated that the 
fuzzy logic methods were better than the linear regression for the prediction of unconfined compressive strength of sand soils injected with microfine cement. When fuzzy logic methods were compared among themselves, it was seen that Sugeno method had a higher prediction performance. Fig. 8 shows the scatterplot of the measured unconfined pressure strength values together with the predictions of the three models. For low values of unconfined compressive strength, it was seen that all three models used for prediction gave close results and showed a good prediction performance. On the other hand, in the region, where the unconfined compressive strength was high, the results of the models were different from each other, and it was seen that there was relatively low prediction success compared to the performance exhibited for small values.

As seen in Fig. 8, the regression model showed lower performance in predicting high unconfined compressive strength values compared to other models. While the highest measured unconfined pressure strength was $23.88 \mathrm{kPa}$, the maximum value predicted by regression analysis was $18.08 \mathrm{kPa}$. In the fuzzy logic model, the difference between the predicted and measured values for both low and high unconfined compressive strength values was low.

\section{Conclusions}

The performance of the developed models (Mamdani method, Sugeno method and Regression analysis) to predict the unconfined compressive strength of sand soils with grouted microfine cement is examined. It is seen that all three give accurate results and they can be used for prediction studies. The $R^{2}$ value is 0.8611 for the regression, 0.8654 for the Mamdani and 0.8709 for the Sugeno models. Although these values are close to each other, the Sugeno method provides relatively better results compared to other models. The mean square error values of the models are calculated as 4.7319 for the regression, 4.5841 for Mamdani and 
4.3962 for Sugeno. These values are in line with the values of the coefficient of determination of the models. The compatibility of both MSE and $R^{2}$ values shows the consistency of the developed models. The prediction performance of all three developed models is high and these approaches can be used in further similar studies. Sugeno model shows the best performance in predicting the unconfined compressive strength of microfine cement grouted sands. This method is followed by Mamdani and Regression models, respectively. This study shows that the fuzzy logic approach is an effective alternative to the traditionally used regression method for prediction problems.

\section{References}

ASTM D4219-02 (2002) Standard Test Method for Unconfined Compressive Strength Index of Chemical- Grouted Soils. ASTM International, West Conshohocken

Avcı, E and Mollamahmutoğlu, M (2019) Syneresis dependent shear strength parameters of sodium silicate grouted sands. Quarterly Journal of Engineering Geology and Hydrogeology 52: 99-109. https://doi.org/10.1144/qjegh2017-080

Çavus SU, Kilit M, Zorluer İ, Edil TE (2019) Fuzzy logic based assessment of seismic soil liquefaction potential and its application to foundations of bridge piers. Journal of Intelligent \& Fuzzy Systems 36(6):6001-6011. https://doi.org/10.3233/JIFS-181795

Christodoulou D, Droudakis A, Pantazopoulos IA, Atmatzidis DK (2009) Groutability and Effectiveness of Microfine Cement Grouts. In:Proceedings of the 17th International Conference on Soil Mechanics \& Geotechnical Engineering, Alexandria, Egypt, https://doi.org/10.3233/978-1-60750-031-5-2232

Chuang PH (1995) Use of fuzzy sets for evaluating shear strength of soils. Computers and Geotechnics 17(4):425-446. https://doi.org/10.1016/0266-352X(95)94914-C 
Elmas Ç (2003) Bulanık Mantık Denetleyiciler (Kuram, Uygulama, Sinirsel Bulanık Mantık). Seçkin Yayınc1lık, Istanbul, Turkey.

Hashimoto K, Nishihara S, Oji S, Kanazawa T, Nishie S, Seko I, Hyodo T, Tsukamato Y (2016) Field testing of permeation grouting using microfine cement. Ground Improvement 169(2):134-142. https://doi.org/10.1680/jgrim.15.00030

Huang YT, Siller TJ (1997) Fuzzy representation and reasoning in geotechnical site characterization. Computers and Geotechnics 21(1):65-86. https://doi.org/10.1016/S0266-352X(95)00013-Z

Karol RH (2003) Chemical grouting and soil stabilization, Marcel Dekker, Brunswick, NJ.

Markou IN, Droudakis AI (2013) Shear Strength of Microfine Cement Grouted Sands. Ground Improvement 166(3):177-186. https://doi.org/10.1680/grim.12.00016

Monjezi M, Rezaei M, Yazdian Varjani A (2009) Prediction of rock fragmentation due to blasting in Gol-E-Gohar iron mine using fuzzy logic. International Journal of Rock Mechanics and Mining 46(8):1273-1280. https://doi.org/10.1016/j.ijrmms.2009.05.005

Nurcayho GW, Shamsuddin SM, Alias RA, Noor Md Sap M. (2003) Selection of Defuzzification Method To Obtain Crisp Value For Representing Uncertain Data In A Modified Sweep Algorithm. Journal of Computer Science and Technology, 3(2):22-28

Perret S, Palardy D, Ballivy G (2003) Rheological behavior and setting time of microfine cement-based grouts, ACI Mater. J., 97(4), 472-478

Reddy PVS, Rao KM, Rani, CS Identification of expansive soils and assessment of expansion potential by fuzzy approach. Electronic Journal of Geotechnical Engineering 14:1-11

Saboya F, Alves MG, Pinto WD (2006) Assessment of failure susceptibility of soil slopes using fuzzy logic. Engineering Geology 86(4):211-224, https://doi.org/10.1016/j.enggeo.2006.05.001 
Schwarz LG, Krizek RJ (1994) Effect of preparation technique on permeability and strength of cement-grouted sand. Geotechnical Testing Journal 17(4):434-443, https://doi.org/10.1520/GTJ10304J

Tekin E (2011) İnce Taneli Çimento (Rheocem 900) Karışımlarının Reolojik Özellikleri. Gazi Üniversitesi Mühendislik Mimarlık Fakültesi Dergisi 26(4):777-785

Warner J (2003) Soil solidification with ultrafine cement grout. In: Proceedings of the third International Conference, Geotechnical Special Publication, Reston, ASCE, February 1012, New Orleans, USA.

Yurtcu Ş, Özocak A (2016) Prediction of compression index of fine-grained soils using statistical and artificial intelligence methods, Gazi Üniversitesi Mühendislik Mimarlık Fakültesi Dergisi, 31(3):597-608, https://doi.org/10.17341/gummfd.95986

Zadeh LA (1965) Fuzzy Algorithms. Information and Control 12(2):94-102, https://doi.org/10.1016/S0019-9958(68)90211-8

Zebovitz S, Krizek RJ, Atmatzidis DK (1989) Injection of fine sands with very fine cement grout. Journal of Geotechnical Engineering 115(12):1717-1733, https://doi.org/10.1061/(ASCE)0733-9410(1989)115:12(1717)

Zorluer İ, Icaga Y, Yurtcu S, Tosun H (2010) Application of a fuzzy rule-based method for the determination of clay dispersibility. Geoderma 160(2):189-196, https://doi.org/10.1016/j.geoderma.2010.09.017 


\section{TABLES}

Table 1. Rules used for Mamdani fuzzy logic model

\begin{tabular}{|c|c|}
\hline No & RULES \\
\hline 1 & $\begin{array}{l}\text { If }(\text { Water/Cement ratio }=\mathrm{VH}) \text { or }(\text { Injection pressure }=\mathrm{VL}) \text { then }(\text { Unconfined } \\
\text { Compressive Strength }=\mathrm{VL})\end{array}$ \\
\hline 2 & $\begin{array}{l}\text { If }(\text { Water/Cement ratio }=\mathrm{H} \text { ) or }(\text { Injection pressure }=\mathrm{L} \text { ) then }(\text { Unconfined } \\
\text { Compressive Strength }=\mathrm{L})\end{array}$ \\
\hline 3 & $\begin{array}{l}\text { If }(\text { Water/Cement ratio }=\mathrm{MH}) \text { or }(\text { Injection pressure }=\mathrm{ML}) \text { then }(\text { Unconfined } \\
\text { Compressive Strength }=\mathrm{ML})\end{array}$ \\
\hline 4 & $\begin{array}{l}\text { If }(\text { Water/Cement ratio }=\mathrm{M}) \text { or }(\text { Injection pressure }=\mathrm{M}) \text { then }(\text { Unconfined } \\
\text { Compressive Strength }=\mathrm{M})\end{array}$ \\
\hline 5 & $\begin{array}{l}\text { If }(\text { Water/Cement ratio }=M) \text { or }(\text { Injection pressure }=M) \text { then }(\text { Unconfined } \\
\text { Compressive Strength }=\mathrm{ML})\end{array}$ \\
\hline 6 & $\begin{array}{l}\text { If }(\text { Water/Cement ratio }=\mathrm{M}) \text { or }(\text { Injection pressure }=\mathrm{MH}) \text { then }(\text { Unconfined } \\
\text { Compressive Strength }=\mathrm{L})\end{array}$ \\
\hline 7 & $\begin{array}{l}\text { If }(\text { Water } / \text { Cement ratio }=\mathrm{ML}) \text { or }(\text { Injection pressure }=\mathrm{MH}) \text { then }(\text { Unconfined } \\
\text { Compressive Strength }=\mathrm{MH})\end{array}$ \\
\hline 8 & $\begin{array}{l}\text { If }(\text { Water/Cement ratio }=\mathrm{ML}) \text { or }(\text { Injection pressure }=\mathrm{M}) \text { then }(\text { Unconfined } \\
\text { Compressive Strength }=\mathrm{M})\end{array}$ \\
\hline 9 & $\begin{array}{l}\text { If }(\text { Water/Cement ratio }=\mathrm{L} \text { ) or }(\text { Injection pressure }=\mathrm{H} \text { ) then }(\text { Unconfined } \\
\text { Compressive Strength }=\mathrm{H})\end{array}$ \\
\hline 10 & $\begin{array}{l}\text { If }(\text { Water/Cement ratio }=\mathrm{VL}) \text { or }(\text { Injection pressure }=\mathrm{VH}) \text { then }(\text { Unconfined } \\
\text { Compressive Strength }=\mathrm{VH})\end{array}$ \\
\hline
\end{tabular}


Table 2. Rules used for Sugeno fuzzy logic model

\begin{tabular}{|c|c|}
\hline No & RULES \\
\hline 1 & $\begin{array}{l}\text { If }(\text { Water/Cement ratio }=\mathrm{VH}) \text { or }(\text { Injection pressure }=\mathrm{VL}) \text { then } \\
(\text { Unconfined Compressive Strength }=-2,3726(\text { Water/Cement ratio })+0,01371 \text { (Injection } \\
\text { pressure })+10,509)\end{array}$ \\
\hline 2 & $\begin{array}{l}\text { If }(\text { Water/Cement ratio }=\mathrm{H}) \text { or }(\text { Injection pressure }=\mathrm{L}) \text { then } \\
(\text { Unconfined Compressive Strength }=-2,5927(\text { Water/Cement ratio })+0,00695 \text { (Injection } \\
\text { pressure })+11,607)\end{array}$ \\
\hline 3 & $\begin{array}{l}\text { If }(\text { Water/Cement ratio }=\mathrm{MH}) \text { or }(\text { Injection pressure }=\mathrm{ML}) \text { then } \\
(\text { Unconfined Compressive Strength }=-1,7885(\text { Water/Cement ratio })+0,0066 \text { (Injection } \\
\text { pressure })+10,597)\end{array}$ \\
\hline 4 & $\begin{array}{l}\text { If }(\text { Water } / \text { Cement ratio }=\mathrm{M}) \text { or }(\text { Injection pressure }=\mathrm{M}) \text { then } \\
(\text { Unconfined Compressive Strength }=-2,2 \quad(\text { Water/Cement ratio })+0,0064 \text { (Injection } \\
\text { pressure })+13,177)\end{array}$ \\
\hline 5 & $\begin{array}{l}\text { If }(\text { Water/Cement ratio }=\mathrm{M}) \text { or }(\text { Injection pressure }=\mathrm{M}) \text { then } \\
(\text { Unconfined Compressive Strength }=-1,7885(\text { Water/Cement ratio })+0,0066 \text { (Injection } \\
\text { pressure })+10,597)\end{array}$ \\
\hline 6 & $\begin{array}{l}\text { If }(\text { Water/Cement ratio }=\mathrm{M}) \text { or }(\text { Injection pressure }=\mathrm{MH}) \text { then } \\
(\text { Unconfined Compressive Strength }=-1,2(\text { Water/Cement ratio })+0,0064 \text { (Injection } \\
\text { pressure })+13,177)\end{array}$ \\
\hline 7 & $\begin{array}{l}\text { If }(\text { Water/Cement ratio }=\mathrm{ML}) \text { or }(\text { Injection pressure }=\mathrm{MH}) \text { then } \\
(\text { Unconfined Compressive Strength }=-2,6936(\text { Water/Cement ratio })+0,0071 \text { (Injection } \\
\text { pressure })+17,538)\end{array}$ \\
\hline 8 & $\begin{array}{l}\text { If }(\text { Water/Cement ratio }=\mathrm{ML}) \text { or }(\text { Injection pressure }=\mathrm{M}) \text { then } \\
(\text { Unconfined Compressive Strength }=-2,1 \quad(\text { Water/Cement ratio })+0,0064 \text { (Injection } \\
\text { pressure })+13,177)\end{array}$ \\
\hline 9 & $\begin{array}{l}\text { If }(\text { Water/Cement ratio }=\mathrm{L}) \text { or }(\text { Injection pressure }=\mathrm{H}) \text { then } \\
(\text { Unconfined Compressive Strength }=1,05 \text { (Water/Cement ratio })+0,010 \text { (Injection } \\
\text { pressure })+9,746)\end{array}$ \\
\hline 10 & $\begin{array}{l}\text { If }(\text { Water/Cement ratio }=\mathrm{VL}) \text { or }(\text { Injection pressure }=\mathrm{VH}) \text { then } \\
(\text { Unconfined Compressive Strength }=5,0092(\text { Water/Cement ratio })+0,02568 \text { (Injection } \\
\text { pressure })+7,3092)\end{array}$ \\
\hline
\end{tabular}


Table 3. The Coefficient of determination $\left(\mathrm{R}^{2}\right)$ and Mean Square Error (MSE) values of the models

\begin{tabular}{cccc}
\hline $\begin{array}{c}\text { Model } \\
\text { No }\end{array}$ & Method & $\begin{array}{c}\text { Coefficient of } \\
\text { determination }\left(\mathbf{R}^{2}\right)\end{array}$ & $\begin{array}{c}\text { Mean Squared Error } \\
(\text { MSE) }\end{array}$ \\
\hline 1 & Regression & 0,8611 & 4,7319 \\
2 & Mamdani & 0,8654 & 4,5841 \\
3 & Sugeno & 0,8709 & 4,3962 \\
\hline
\end{tabular}




\section{FIGURES}

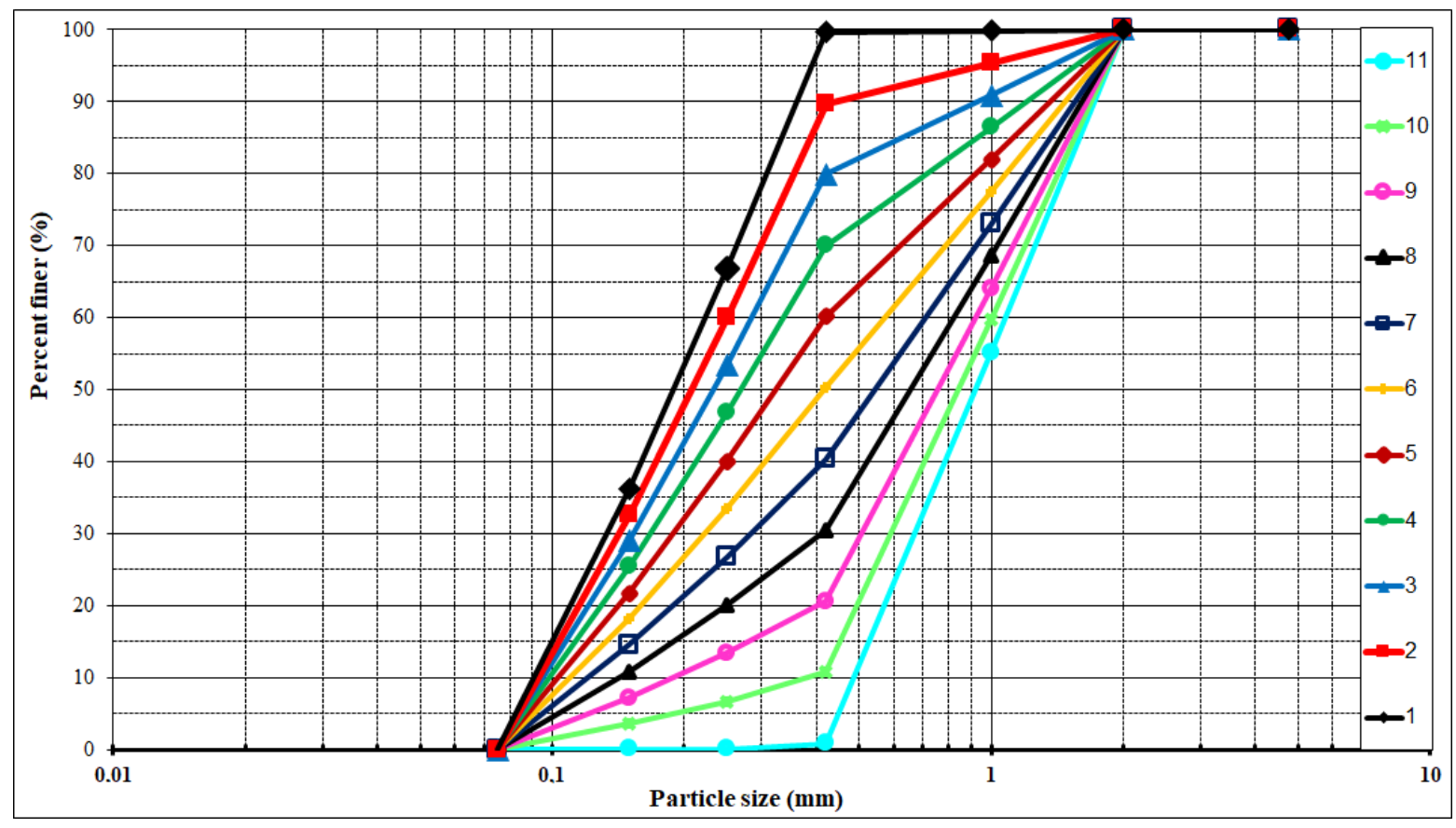

Fig. 1. Gradation curves of sands used in experiments 


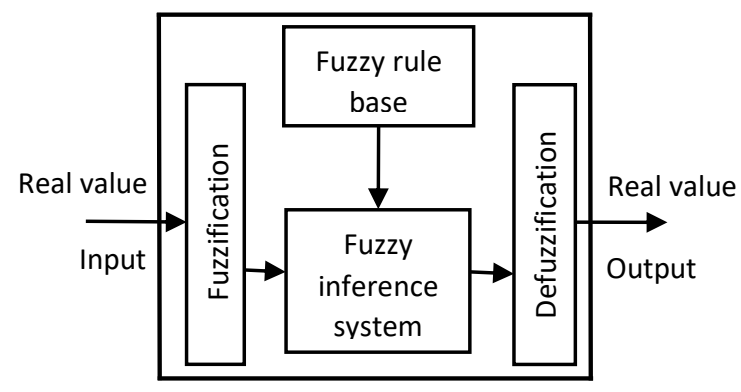

Fig. 2. The Scheme of Fuzzy Inference System (FIS) 


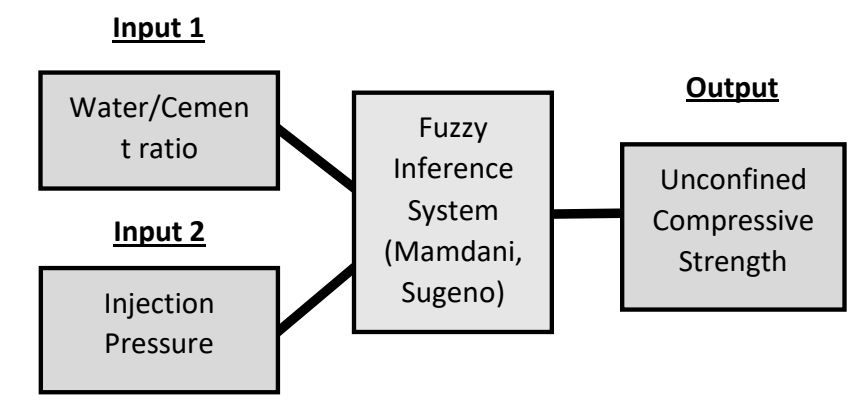

Fig. 3. The schematic representation of the fuzzy logic models (Mandani and Sugeno) 
(a)

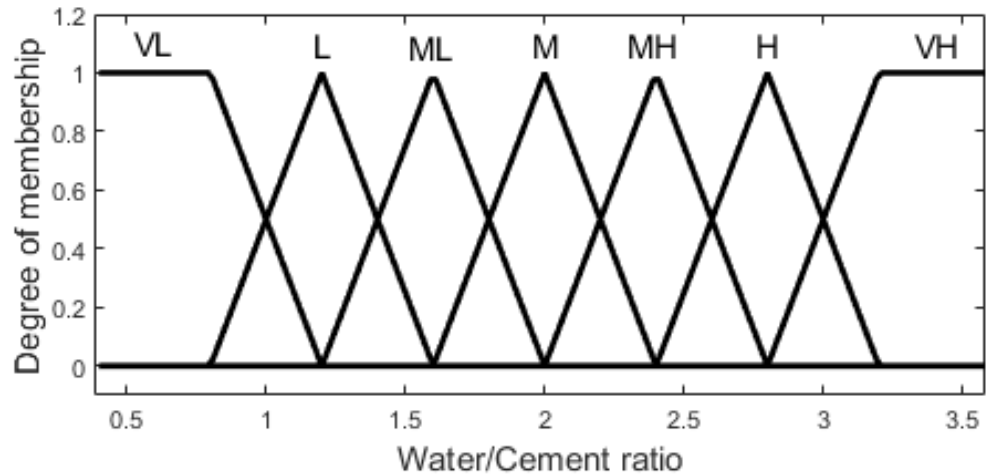

(b)

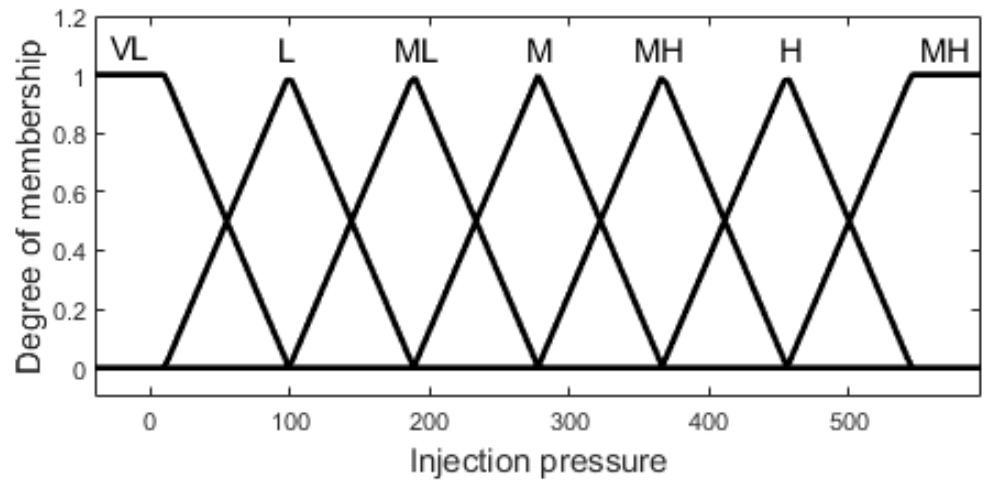

(c)

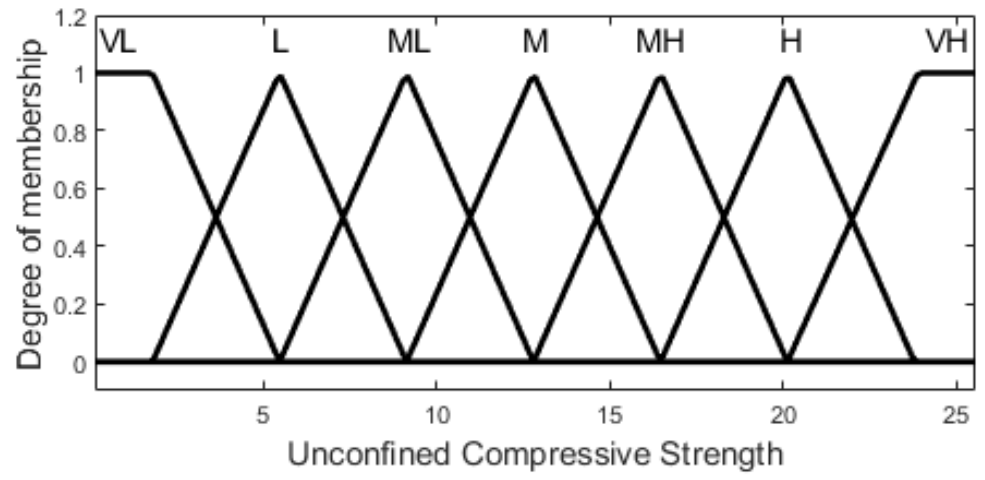

Fig. 4. Membership functions and degrees of inputs and outputs used in fuzzy logic models, Inputs: (a) Water/Cement ratio and (b) Injection pressures ( $\mathrm{kPa}$ ), Outputs: (c) Unconfined Compressive Strength (UCS) (MPa) 


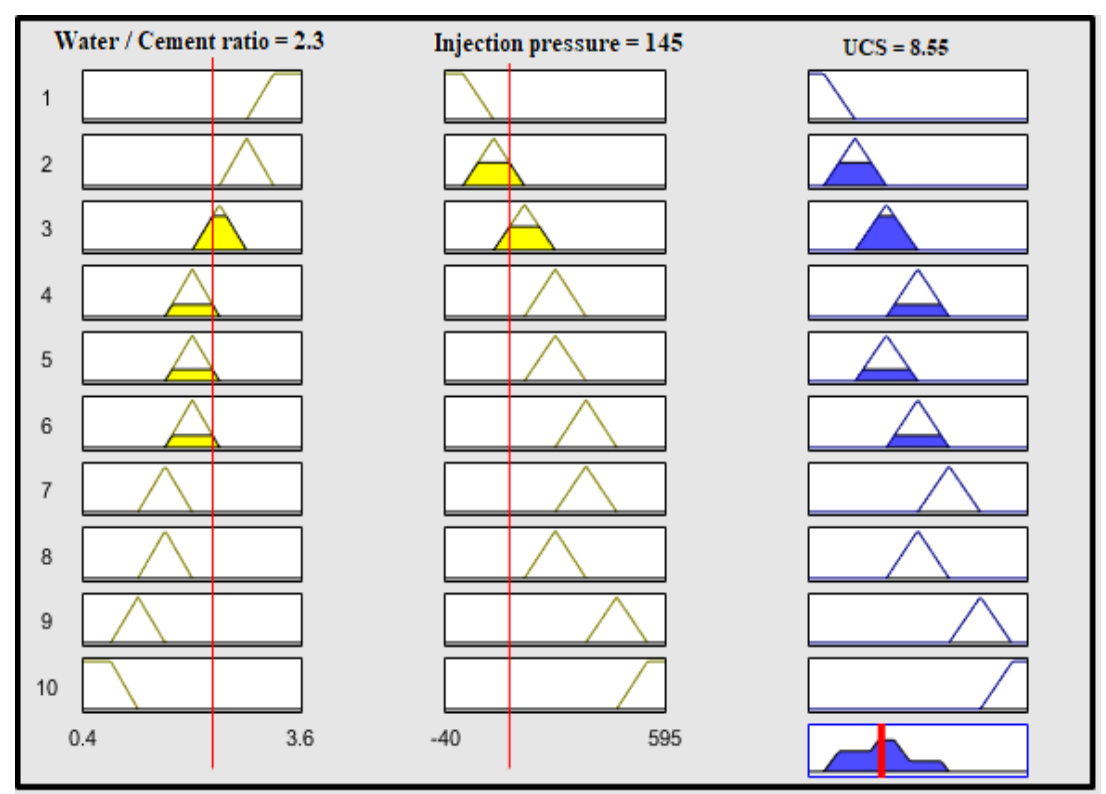

(a)

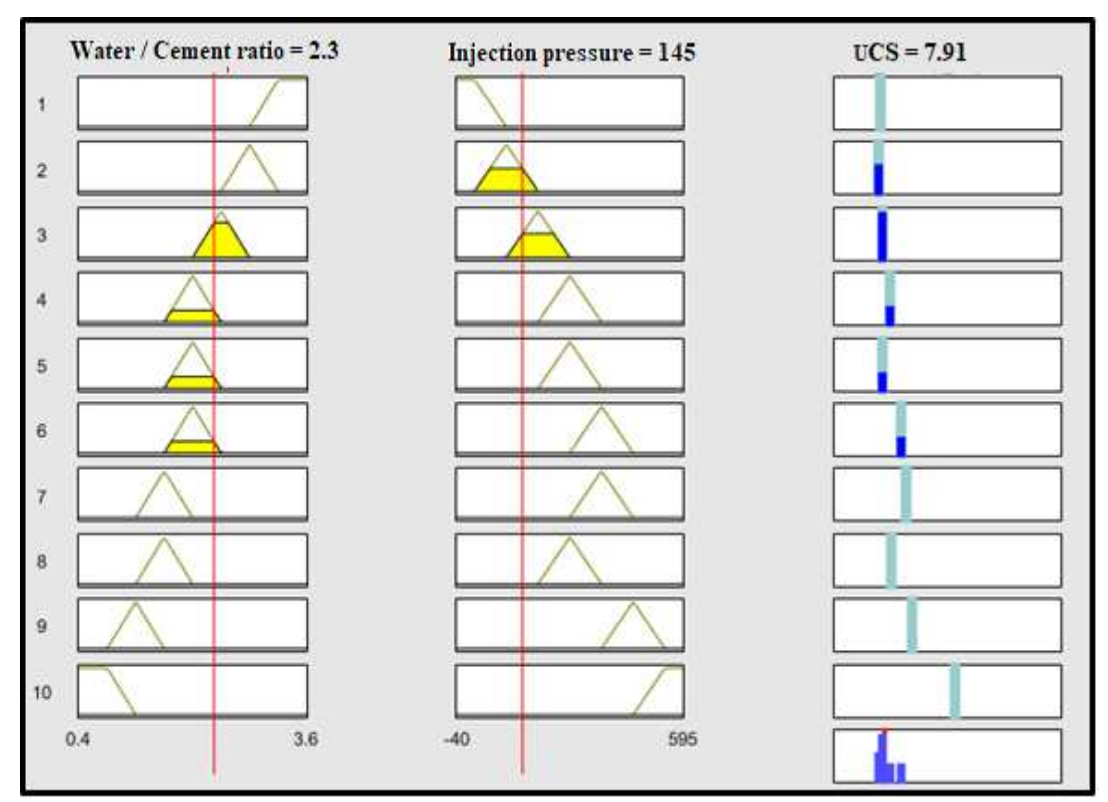

(b)

Fig. 5. Graphic indication of the calculation of outputs in fuzzy logic models (e.g. Water/Cement=2.3 and Injection pressure $=145 \mathrm{kPa}$ ), (a) Mamdani model, (b) Sugeno model. 
(a)

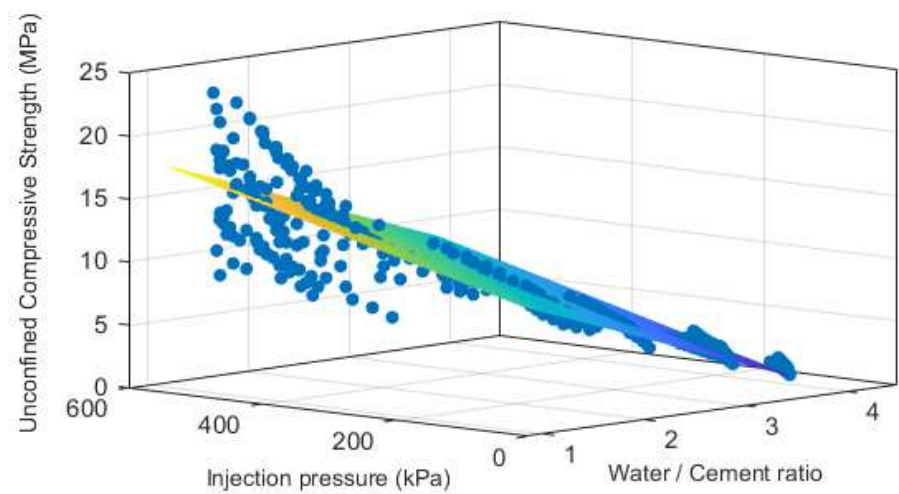

(b)

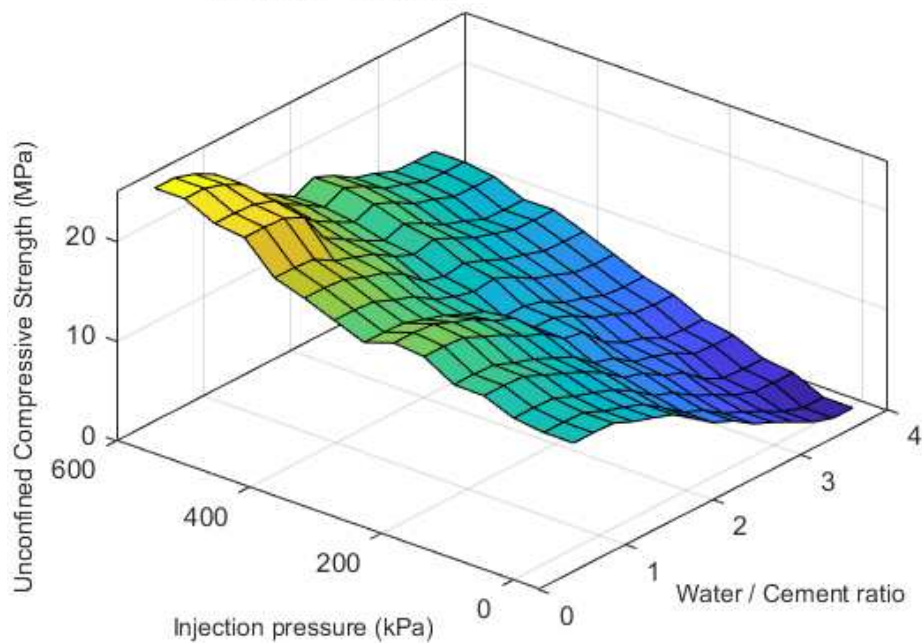

(c)

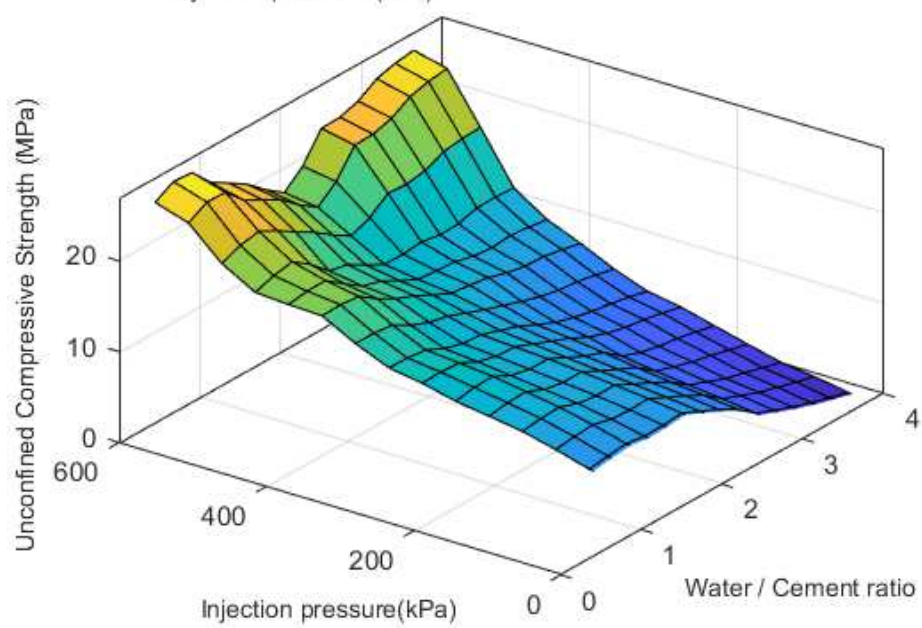

Fig. 6. Three dimensional graphs of multiple linear regression and fuzzy logic models (Mamdani and Sugeno). Surface viewer (Input: Water / Cement ratio and Injection pressure (kPA) versus Output: Unconfined Compressive Strength (MPa)) of (a) Regression, (b) Mamdani and (c) Sugeno 
(a)

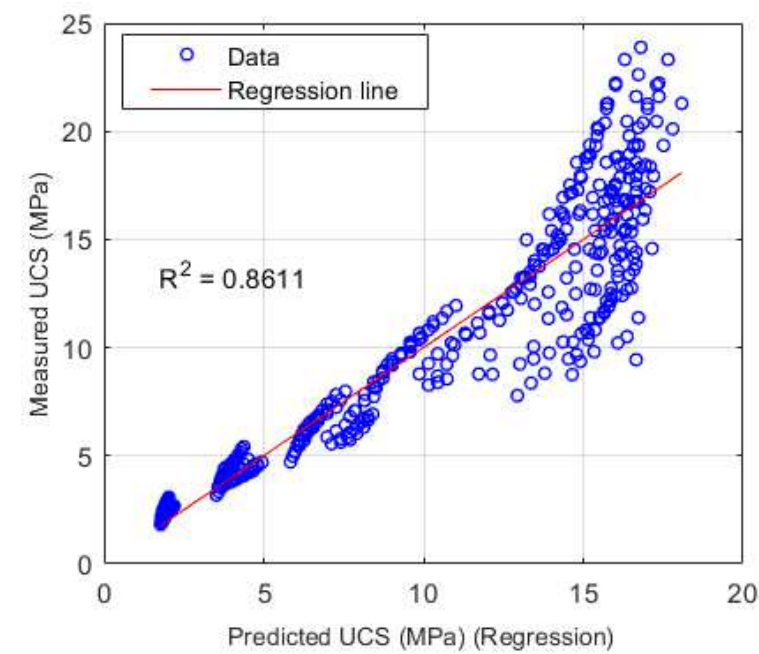

(b)
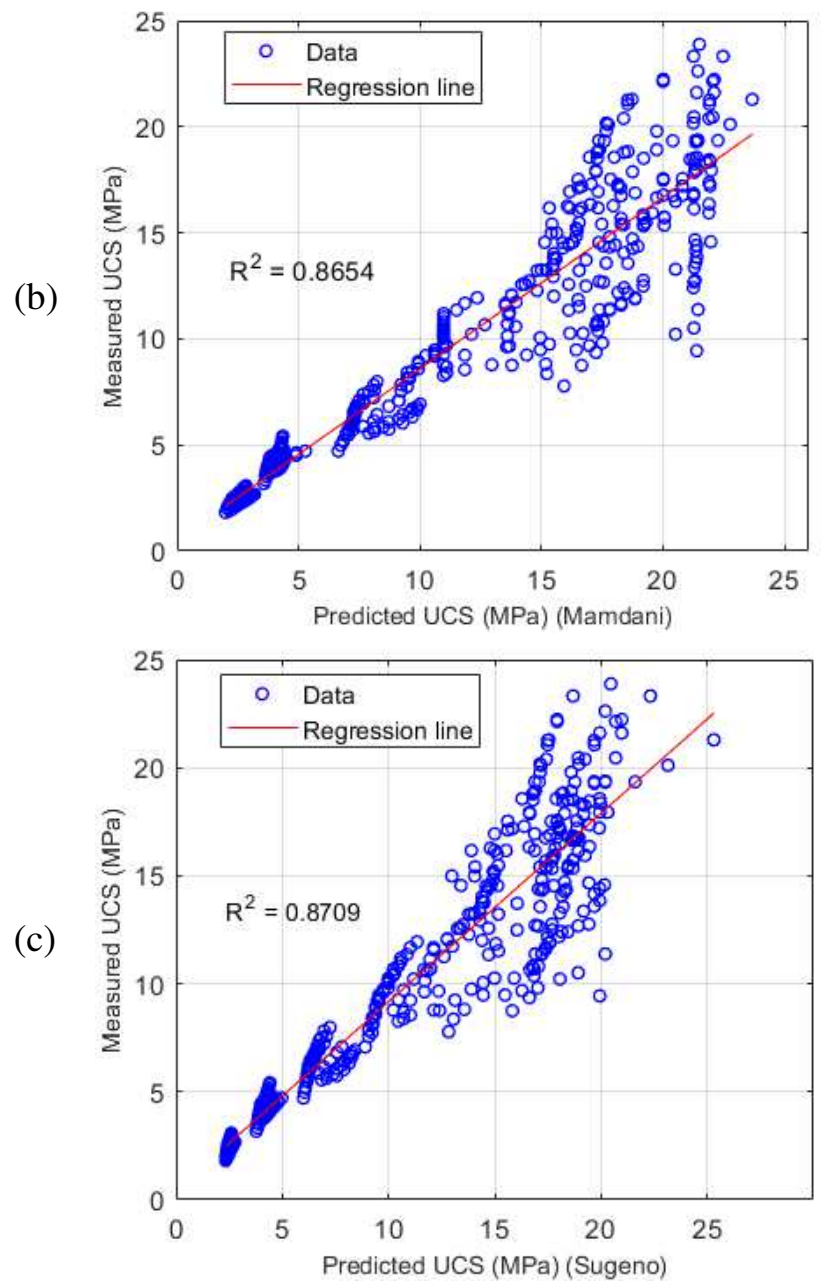

Fig. 7. Comparison of measured and predicted USC (MPa) using (a) Multiple regression modelling, (b) Mamdani fuzzy logic modelling and (c) Sugeno fuzzy logic modelling. 


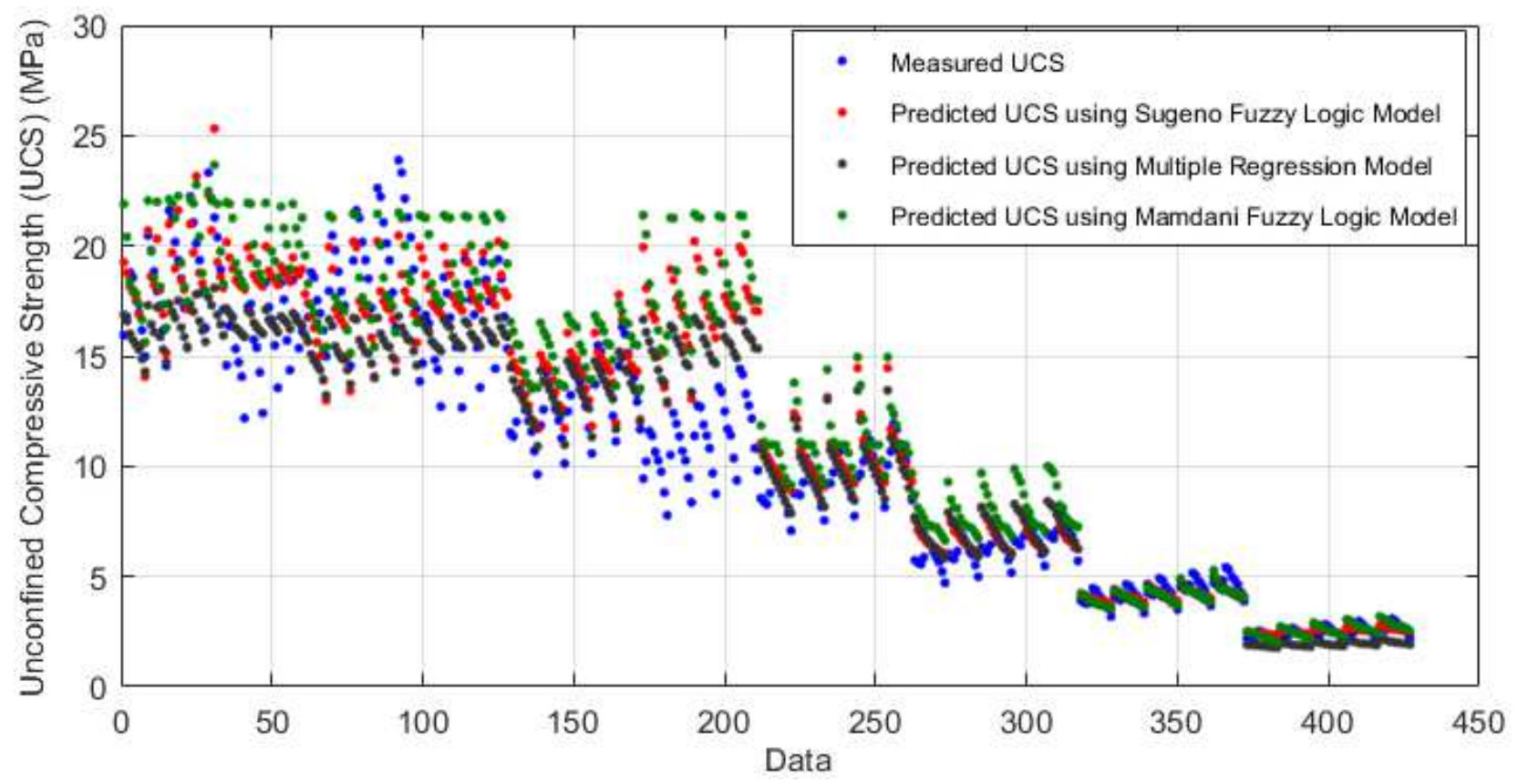

Fig. 8. Measured and Predicted Unconfined Compressive Strength values (USC) from Multiple Regression, Mamdani and Sugeno Fuzzy Logic Models. 